\title{
A EDUCAÇÃO COMO ARMA CONTRA O OBSCURANTISMO
}

\author{
EDUCATION AS A WEAPON AGAINST DARKNESS
}

\author{
Vilson Aparecido da Mata ${ }^{1}$ \\ Universidade Federal do Paraná (UFPR)
}

\section{RESUMO}

O texto aqui apresentado fez uma análise do modo pelo qual se constituiu um projeto educacional para a sociedade burguesa em seus primórdios. Esse projeto era fundamental na luta pela efetivação da nova sociedade, que procurava superar o obscurantismo medieval por meio, entre outros, da formação de indivíduos com conhecimentos de rudimentos das ciências e, para tanto, era preciso aprender a ler, fazer operações matemáticas e conhecer as leis da natureza. Para a burguesia ascendente, o conhecimento científico foi instrumento para a formação de pessoas capazes de melhor se conduzirem em meio às novas relações sociais, negando as antigas instituições feudais e fundando as novas instituições burguesas. Desse modo, foram resgatados aspectos do pensamento de Marx, Engels, John Locke, JeanJacques Rousseau, Michel de Montaigne e Condorcet. Entre os elementos abordados que deram forma à linha de reflexão para este artigo, o caráter histórico da educação, o processo de mudanças imanente à formação humana e a perspectiva de que a educação transformadora deve compor um projeto de sociedade foram definidos como fulcrais ao melhor entendimento da constituição da educação burguesa como instrumento de transformação da sociedade. A conclusão apontou para a mudança na abordagem da educação, pela burguesia, conforme mudou também sua posição histórica: como classe social revolucionária, a educação compunha um projeto de transformação, porém, uma vez sedimentada a sociedade capitalista burguesa, a educação tornou-se conservadora e dedicada à formação e qualificação profissional, despida de seus elementos transformadores.

Palavras-Chave: Fundamentos da Educação; Filosofia; História.

\section{ABSTRACT}

The text that follows presents an analysis by which the constitutional project to the bourgeois society was constituted in its beginning. This project was fundamental in the

1 Doutor em Educação. Docente do curso de Licenciatura em Educação Física da Universidade Federal do Paraná (UFPR).

Cadernos GPOSSHE On-line, Fortaleza, v. 2, n. Especial, 2019. 
fight for the realization of a new society, which sought to overcome the medieval obscurantism by, among other things, the formation of individuals knowlegeable about the rudiments of the science and, for this purpose, it was necessary to learn how to read, to calculate and to know about the laws of nature. To the ascending bourgeois the scientific knowledge was instrument to the formation of people who were more capable of conveying among the new social relations, denying the old feudal institutions and founding the new bourgeois ones. Therefore, some aspects of Marx, Engels, John Locke, Jean-Jacques Rousseau, Michel de Montaigne and Condorcet thoughts were rescued. Among the rescued elements which provided the reflection for this article, the historical character of education, inherent to the human formation and the perspective that the transforming education shall compose a project of society defined as fundamental to the human formation and the perspective of a better understanding of the constitution of the bourgeois education as an instrument of transformation of society. The conclusion led to a change in the approach to education, by the bourgeois, also changing its historic position: as a revolutionary social class, education was part of a transformation project, however, once the bourgeois capitalist society was sedimented, education became conservative and dedicated to the formation and professional qualification, without its transforming elements.

Keywords: Fundaments of Education; Philosophy; History.

\section{Introdução}

/arl Sagan, cientista e divulgador da ciência estadunidense, em um livro chamado O Mundo Assombrado pelos Demônios, de 1996 (edição brasileira utilizada é de 2002), tece, preocupado, considerações sobre o obscurantismo crescente em seu país. Entre as questões apresentadas, a permanência das pseudociências, o crescimento da anticiência, a timidez das iniciativas que visam tornar a ciência acessível à população e as possibilidades e esperanças que deposita em um processo educacional com foco no conhecimento da realidade são os principais pontos para os quais dirige sua reflexão.

Sobre a educação (em um sentido lato), Sagan (2002) narra a história de Frederick Bailey (depois, Frederick Douglass), importante escritor, abolicionista, orador e ativista pelos direitos humanos nos EUA do século XIX. Bailey nasceu escravo e foi separado de sua família ainda muito criança (prática comum naquela sociedade escravagista), saindo de uma vida de trabalho rural para se tornar um escravo doméstico em uma grande cidade. Nessa nova rotina, Bailey "descobriu" a alfabetização ao ter contato com as cartilhas dos filhos do senhor da casa. Ele estudou essas cartilhas e recebeu alguma ajuda da filha do seu "dono". A descoberta da leitura levou Bailey, segundo Sagan (2002), do obscurantismo da escravidão à liberdade do livre pensar.

Lendo, Bailey descobriu haver estados no país que já haviam abolido a escravidão. Fugiu para um deles, mudou de nome, estudou mais e se tornou uma figura expressiva na luta contra o escravagismo, pelos direitos das mulheres e contra o conservadorismo sulista. A alfabetização, para Sagan (2002), transformou a vida de Bailey. Já com novo nome, agora Douglass, ensinava outros escravos fugidos a ler e escrever, ensinava sobre a necessidade da luta para a conquista da liberdade e sobre como tal luta não pode deixar de ter por base o conhecimento, que se iniciava pela

Cadernos GPOSSHE On-line, Fortaleza, v. 2, n. Especial, 2019. 
alfabetização: "Frederick Douglass ensinou que a alfabetização é o caminho da escravidão para a liberdade. Há muitos tipos de escravidão e muitos tipos de liberdade. Mas saber ler é o caminho" (SAGAN, 2002, p. 352).

É evidente que não se trata somente de saber ler e escrever. Este é, sem dúvida, o caminho, porém, nele outras tantas capacidades devem ser formadas. Tratar dessas capacidades constitui outro objeto que não o deste artigo. A narrativa de Sagan revela que, a partir da apropriação da leitura, é possível alçar o pensamento a patamares de compreensão da realidade capazes de desvendar as elusivas aparências postas diante dos olhos. Apropriação da leitura é aquisição do instrumento de compreensão da essência do real. E desenvolvimento da capacidade de ver 0 mundo com a razão, com o rigor necessário ao desvendar das enganosas aparências e da falsa naturalidade das relações sociais.

A apropriação da leitura revela aqui a apropriação daquilo que foi produzido historicamente pelo ser humano ao longo dos séculos, revela que as mudanças são inevitáveis na marcha histórica da humanidade e que a possibilidade de um projeto para um mundo diferente existe e deve ser concretizada. Trata-se de buscar 0 entendimento de que a civilização é uma criação humana e, portanto, pode ser transformada pelos seres humanos. Isso depende de um processo para a formação de indivíduos capazes de compreender a realidade para além das aparências.

Um sistema educacional, uma direção para a formação do indivíduo, é necessária para a constituição de mudanças profundas. A mudança constitui a própria essência do ser social, tanto na esfera singular do indivíduo quanto na universalidade das relações sociais. A formação de indivíduos capazes de encaminhar transformações sociais e de adaptarem-se às novas realidades decorrentes dessas transformações foi tarefa histórica da educação na passagem para a moderna sociedade capitalista burguesa. A insatisfação com a sociedade existente, a apreensão do acúmulo histórico de conhecimentos produzidos pela humanidade e o projeto para uma formação humana em tudo diferente daquela do Antigo Regime, foram o combustível para os projetos educacionais elaborados pela burguesia em ascensão. A constituição da educação formal como instituição burguesa, cujo horizonte era a superação das superstições, dos dogmas, das concepções monolíticas a respeito da realidade, enfim, do obscurantismo da Idade Média, foi o caminho trilhado neste artigo. $O$ intuito foi demonstrar que a educação se constituiu como um poderoso instrumento para a emancipação política no período revolucionário da burguesia, pois compunha um projeto de transformação social.

Esses elementos acima mencionados (história, mudança, projeto) formam três entre tantos outros que compõem a educação. São destacados neste texto a fim de considerar o fato de que a educação, nos primórdios da sociedade burguesa, era apresentada como instrumento fundamental na luta contra o obscurantismo medieval. É pela educação que os ideais de liberdade, de democracia, a ciência, a filosofia e o espírito de humanização do ser humano podem ser internalizados por todos os indivíduos. Em um momento de revisionismo histórico, de negação do conhecimento, das ciências e das artes; em um momento de ascensão do fundamentalismo religioso e do obscurantismo e de ataques à educação, retomar seus primórdios é rever o projeto para a formação de um sistema educacional autônomo, socialmente referenciado e formador de indivíduos capazes de se conduzir em uma sociedade que, apesar de suas contradições, efetivou a emancipação política.

Com isto, apresenta-se o texto na seguinte sequência: o primeiro tópico elabora reflexões a respeito do caráter histórico da educação a partir de Marx e Engels; o segundo chama a atenção para as mudanças que o processo educacional encaminha

Cadernos GPOSSHE On-line, Fortaleza, v. 2, n. Especial, 2019.

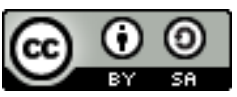


a partir das recomendações educacionais de Locke e Rousseau e, no terceiro tópico, procura-se demonstrar que toda mudança social demanda um projeto, recuando até Montaigne, bem como apresentar a efetivação desse projeto já como tarefa da nova sociedade, com Condorcet. Por fim, elaboram-se reflexões sobre os limites da educação burguesa e o recuo de seus princípios revolucionários.

\section{Educação e Formação Humana: ser humano é ser histórico}

Marx e Engels (2013) afirmam que a única ciência por eles reconhecida é a ciência da história. Com isso, estabelecem um caminho a partir do qual a cultura humana deve ser investigada levando em conta as condições objetivas que engendram a realidade. $O$ caráter histórico da educação deve trilhar esse mesmo caminho. Em sentido amplo, educar constitui transmitir conhecimentos de uma geração mais velha para a geração mais jovem. Sejam esses conhecimentos transmitidos tácita ou formalmente; de forma empírica ou reflexiva; no dia a dia do trabalho ou em instituições específicas, carregam em si a marca da marcha histórica da humanidade ${ }^{2}$.

A educação é uma parte fundante da formação da própria condição humana civilizada. Entretanto, é preciso adentrar seus significados e sentidos nas determinações materiais, evitando as armadilhas das concepções ilusórias e fenomênicas. O caráter histórico da educação deve tomar como ponto de partida a produção da vida real. Agindo sobre a natureza, os indivíduos produzem relações sociais, transmitem entre si conhecimentos, transformando-os, modificando-os e construindo o mundo humano. No debate travado com Feuerbach a respeito da história humana, Marx e Engels (2013) demonstram que o fazer humano e as condições nas quais a sociedade se encontra são produções humanas, ou, nas palavras dos autores: "o resultado da atividade de toda uma série de gerações, que, cada uma delas sobre os ombros da precedente, desenvolveram sua indústria e seu comércio e modificaram sua ordem social de acordo com as necessidades alteradas" (MARX e ENGELS, 2013, p. 30).

Aqui parece haver uma questão fulcral para se entender a educação como processo histórico: o que significa afirmar que uma geração desenvolve sua indústria ${ }^{3}$ "sobre os ombros da precedente"? Antes de tudo, significa entender que existe uma anterioridade, e que, portanto, as gerações mais jovens constroem seu mundo a partir do acúmulo das gerações anteriores. Para tanto, alguma sistematização para a transmissão do acúmulo histórico é condição sem a qual não há desenvolvimento (produção do novo) social. História aqui significa que, a cada geração, os seres humanos precisam retomar e renovar as conquistas de seus antepassados.

Para Marx e Engels (2013), a condição para que haja história é a existência de indivíduos humanos, de sua complexidade corporal. Seres humanos reais, agindo sobre a natureza, transformando-a em comida, bebida, vestimentas, abrigo, etc., são necessários para que a história seja possível. A produção da existência é o primeiro e mais fundamental ato histórico, porque demanda que conhecimentos acumulados sejam transmitidos, partilhados, apropriados pelos indivíduos e isso implica um

\footnotetext{
2 Importante frisar que tais oposições não podem ser consideradas como extremos irreconciliáveis ou tomadas isoladamente. São, antes, polos dialéticos que se interpenetram e se determinam, a divisão aqui tem por objetivo encaminhar a reflexão.

3 Entendido aqui o termo "indústria" como o conjunto de atividades econômicas que pressupõem habilidade, aptidão, destreza para a manipulação e transformação da matéria prima em produtos e bens necessários à realização humana pelo trabalho, pela arte, pela reflexão, pela religião, etc.
}

Cadernos GPOSSHE On-line, Fortaleza, v. 2, n. Especial, 2019.

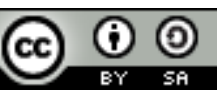


intercâmbio entre as pessoas: "um ato histórico, uma condição fundamental de toda a história, que ainda hoje, assim como há milênios, tem de ser cumprida diariamente, a cada hora, simplesmente para manter os homens vivos" (MARX e ENGELS, 2013, p. 33).

Uma segunda condição, que deriva da primeira, é que na transformação da natureza em coisas socialmente necessárias, os seres humanos satisfazem carências e, simultaneamente, produzem novas carências. Novas necessidades decorrem, então, do provimento de necessidades anteriores, isso significa que é preciso apropriar-se de condições, instrumentos, contextos e conhecimentos indispensáveis. O novo só pode ser produzido a partir da apropriação daquilo que foi produzido pelas gerações anteriores. Na formulação dos autores alemães: "a satisfação dessa primeira necessidade e o instrumento de satisfação já adquirido conduzem a novas necessidades - e essa produção de novas necessidades constitui o primeiro ato histórico" (MARX e ENGELS, 2013, p. 33).

Entre as novas carências produzidas, devem ser incluídos aqueles elementos que, aparentemente, não estão relacionados com o ato de transformar a natureza, como, por exemplo, a complexificação das formas de comunicação entre os indivíduos, ou, a linguagem; a carência de beleza, porque não basta que o objeto produzido seja útil, ele deve ser belo, ou, a estética; a carência de sentido e de valorização daquilo que é produzido como sendo bom ou mal, útil ou inútil, necessário ou acessório, ou, a moral.

Esses elementos podem ser verificados no terceiro momento apresentado por Marx e Engels (2013), aquele no qual o ser humano, que já reproduz sua vida no trabalho, deve reproduzir biologicamente a vida, ou, criar outros seres humanos. A criação de novos indivíduos é, desde o início, ato histórico cingido pelo trabalho, pela linguagem, pela estética, pela moral. A produção da vida (seja a própria ou a de outros) é uma relação, ao mesmo tempo, natural e social (MARX e ENGELS, 2013).

Natural porque todos os seres vivos são dotados da capacidade de reproduzir a vida. Biologicamente, o corpo humano é capaz de gerar outros corpos humanos. Mas isso não é suficiente para garantir a sobrevivência da espécie, pois não há força física, velocidade, tamanho, sentidos, etc., capazes de fazer frente aos demais seres da natureza (KLEIN, SILVA e DA MATA, 2012). Foi apesar e por consequência dessas limitações do corpo humano que se tornou indispensável potencializar outras capacidades. Esse esforço permitiu à espécie humana estabelecer uma relação com a natureza completamente nova e diversa na história da vida: o trabalho.

Pelo trabalho, o ser humano tornou-se capaz de produzir para além de seus limites biológicos e a produção da vida passa a ser social. Embora não abandone seu caráter natural, o aspecto social torna-se predominante (LEONTIEV, 1978). "Ou seja, o processo de trabalho busca transformar a matéria natural em produtos que atendam às necessidades humanas. Em outros termos, o trabalho é o processo pelo qual o homem atribui ou imprime finalidades humanas aos elementos da natureza" (KLEIN, SILVA e DA MATA, 2012, p. 219).

Para Marx e Engels (2013), a história humana é uma construção contínua e acumulativa dos seres humanos. A produção de novas carências só pode existir em sociedade, a partir da produção da vida ao longo de muitas gerações. Para tal acúmulo chegar às novas gerações, é preciso que haja uma sistematização para a sua transmissão. Esse caráter histórico é inseparável da concepção de educação como parte fundamental da formação humana. Leontiev (1978) entendeu bem essa questão. A transmissão do acúmulo histórico deve ser ato intencional: o que ensinar? O que tem importância e merece ser transmitido às novas gerações? Para que uma 
sociedade tenha identidade, é preciso que os produtos da objetivação humana sejam tratados como conhecimentos que devem ser mantidos sob a guarda coletiva da experiência humana. Isso dá um caráter acumulativo ao processo educacional, mas não monolítico. "Cada geração começa, portanto, a sua vida num mundo de objetos e de fenômenos criados pelas gerações precedentes" (LEONTIEV, 1978, p. 265). Em outras palavras, o conhecimento da atividade produtiva, tanto em seus aspectos concretos quanto simbólicos, devem ser mantidos pelas gerações mais jovens, pois são vitórias coletivas sobre os limites da biologia. Nas palavras de Mészáros:

A atividade produtiva é, portanto, o mediador na "relação sujeitoobjeto" entre homem e natureza. Um mediador que permite ao homem conduzir um modo humano de existência, assegurando que ele não recaia de volta na natureza, que não se dissolva no "objeto" (MÉSZÁROS, 2006, p. 79. Grifos do autor).

É preciso ensinar às gerações mais jovens aqueles elementos que resultam da atividade humana e que não representem retrocesso civilizacional, ou, que não representem a dissolução do humano. O caráter histórico da educação é alento humano, alerta dos antepassados e resistência do presente, é a mudança. Um processo histórico é mudança, transformação, superação de condições anteriores, impulso a partir de uma base já existente em direção ao novo. A complexificação das relações sociais estabelece a necessidade de que se construam instâncias capazes de garantir que a própria sociedade exista.

\section{A Mudança que se quer: educação é transformadora}

A mudança começa, então, a partir daquilo que é legado do passado, que precisa ser apropriado, dominado, compreendido, para então ser transformado, negado, reorganizado. Produzir o novo requer problematizar, arguir e, eventualmente, destruir o velho. Começar a viver em um mundo de fenômenos e objetos criados pelas gerações anteriores (LEONTIEV, 1978) ou, sobre os ombros da geração precedente (MARX e ENGELS, 2013) significa escolher, a cada nova era, quais os ideais a serem perseguidos, qual o tipo de ser humano desejado e quais ações serão necessárias para implementar as mudanças. A passagem da sociedade medieval para a modernidade exprime como a nova era necessitava negar, criticar e destruir a velha ordem feudal, monárquica, absolutista, dando corpo e sustentação às aspirações de uma nova sociedade mais racional e, por isso, necessitando formar pessoas com nova lógica de pensamento; mais livre e, por isso, precisando formar pessoas emancipadas do jugo feudal; mais produtiva e, por isso, demandando indivíduos mais criativos e engenhosos.

A tarefa que se punha diante da burguesia, classe ascendente e revolucionária, era encaminhar a mudança nos fundamentos do modo de produção feudal. A educação, nos marcos e nos limites daquele momento histórico, foi convocada à defesa dos interesses do progresso social e contra o obscurantismo medieval. Entre os pensadores que expressam essa mudança e essa luta pela superação do velho, destacam-se aqui dois: John Locke (1632-1704) e Jean-Jacques Rousseau (17121778). Esses filósofos são importantes por serem pilares do pensamento ocidental e da própria formação da democracia liberal. Ademais, suas reflexões sobre a formação humana e a educação encaminham as mudanças desejadas e necessárias à 
efetivação da sociedade burguesa, combatendo o obscurantismo de sua época, eles nos convidam a refletir sobre o obscurantismo que ronda nosso tempo.

O século XVII foi palco de mudanças importantes em vários campos. Desde descobertas científicas até a proposição de novas abordagens filosóficas e, de modo lapidar, mudanças políticas que encaminharam a modernidade. Nesse contexto de transformações e ascensão da burguesia viveu John Locke que, por sua defesa do liberalismo político é considerado um dos pais do estado moderno; por sua convicção de que a razão fosse o instrumento capaz de levar os homens da selvageria à civilidade, é um dos precursores do lluminismo e, por suas reflexões de que somente a experiência prática é capaz de produzir conhecimentos verdadeiros, excluindo a intuição, a fé e os mitos, é um dos fundadores do empirismo inglês.

Defensor aguerrido do liberalismo político, Locke é inimigo do feudalismo e do absolutismo, bem como da ingerência da religião nas questões referentes ao Estado. Para Locke (1986), o poder político e a religião devem permanecer tão separados quanto a terra e o céu. Por isso mesmo, em sua atuação como preceptor de filhos de vários nobres e burgueses, rechaçou a escolástica, forma clássica da formação da nobreza medieval, negando-a e propugnando uma educação mais enraizada no mundo, mais científica e mais moral. Ele, imbuído dos ideais desse contexto, queria forjar o "novo homem".

A nova sociedade burguesa demandou a negação e destruição daquilo que já se mostrava caduco. A educação é convocada para a tarefa de contribuir com a mudança. Em Locke (1986), essa mudança tem como base os cuidados com o corpo, a moral e o desenvolvimento cognitivo dos filhos da nobreza esclarecida e dos burgueses em ascensão. A educação deve formar costumes, dirigir-se ao domínio da natureza, superando o estado natural. Trata-se da formação do indivíduo devotado à conquista do sucesso nos negócios.

Para Locke (1986), educação é aprimoramento pessoal para o sucesso no mundo novo e demanda que se aprenda a analisar e julgar os outros indivíduos, a fim de obter vantagem nos negócios. Conhecer as intenções do outro pressupõe o conhecimento da natureza humana, que, para o empirismo, significava entender a estrutura da mente, formada a partir da experiência sensorial. Uma vez que tudo que está na mente é proveniente da educação, esta passa a ocupar um lugar de destaque tanto na formação da consciência como na capacidade de entender o pensamento dos demais. O tutor, ou preceptor, deve ensinar seu discípulo "a julgar os homens com sanidade, segundo os signos que servem melhor para descobrir seu verdadeiro caráter, e que fazem penetrar em seu foro íntimo" (LOCKE, 1986, p. 127).

A mudança na educação que Locke quer demanda a preparação do homem de negócios, em tudo oposto ao ideal de formação da velha sociedade. O indivíduo interessado unicamente em suas possibilidades de sucesso, individualista, uma mônada, é o novo, é a negação das bases da velha ordem. A educação é a forma pela qual se impõe o conhecimento verdadeiro sobre o obscurantismo medieval. Embora o destino de suas orientações educacionais seja os filhos dos nobres e burgueses (a formação do Gentleman), Locke (1986) propõe uma formação que nega o saber acumulado, nas não o conhecimento, que advém da experiência sensorial e da racionalização científica; nega a dureza e o ascetismo da escolástica, mas não a disciplina e a severidade, indispensáveis ao sucesso pessoal; nega a mortificação do corpo, mas não sua preparação para o mundo e para os negócios, necessária ao negociante que viaja, descobre novos sabores, novos climas, novos mundos.

O propósito da educação é o domínio da natureza, tanto a externa quanto a própria natureza humana. Pela formação de costumes, o indivíduo deve aprender a

Cadernos GPOSSHE On-line, Fortaleza, v. 2, n. Especial, 2019.

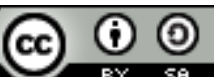


não mais negar as paixões, mas controla-las: "o mal não é ter desejos apropriados às exigências e ideias de cada idade; o mal é não saber submeter esses desejos às regras e restrições da razão" (LOCKE, 1986, p. 68). A razão é elevada à condição de reguladora das ações, em lugar da moral religiosa. A razão é a mudança. Daqui em diante, a formação do novo homem demandará uma formação racional, não mais baseada nos dogmas da fé; uma formação moral e ética independente dos mandos religiosos; um conhecimento efetivo da natureza e não mais das escrituras sagradas como orientação para o entendimento do mundo.

John Locke sintetiza e exprime um processo de mudança fundamental para o entendimento do papel transformador que a educação assume em um contexto social cuja necessidade é tomar novas direções. A negação da ordem feudal não significou abandona-la por completo, mas supera-la por assimilação. O processo de mudança exige que se apreenda aquilo que foi historicamente construído para que sua negação seja capaz de superar limites, transformar a realidade e dar nova orientação à sociedade.

Essa direção para a mudança foi também seguida por Jean-Jacques Rousseau no século XVIII. Considerado um dos mais destacados pensadores iluministas, o filósofo suíço é também um dos precursores do romantismo e um atento pensador político para quem a soberania de um país deveria residir em seu povo. Como iluminista, Rousseau cria na razão contra o obscurantismo que ainda mantinha no poder do Estado monarcas absolutistas e cortes impregnadas de privilégios.

Libertário, Rousseau combateu as antigas concepções religiosas e postulou, para a organização da sociedade, uma estrutura que preservasse os bons instintos humanos. Por suas convicções, foi perseguido e seus livros incinerados, somente anos após sua morte, as ideias desse pensador foram resgatadas e tiveram influência significativa para a revolução francesa. Rousseau queria a mudança, queria uma sociedade livre das amarras feudais, mas livre também do jugo das instituições burguesas: "o homem civil nasce e morre na escravidão; enquanto conservar a figura humana, está acorrentado por nossas instituições" (ROUSSEAU, 1995, p. 16).

Filósofo da liberdade plena, o suíço entendia que ela já teria existido no estado de natureza e se perdeu quando, pela complexificação das relações, a sociedade e a propriedade privada corromperam-na, bem como o altruísmo e a pureza dos seres humanos (ROUSSEAU, 1999). A ascensão da sociedade é também o momento do homem degenerado e dependente, desligado de sua essência:

O único que faz a sua vontade é aquele que não precisa para tanto colocar o braço de outrem na ponta dos seus. Segue-se daí que o primeiro de todos os bens não é a autoridade, mas a liberdade. $O$ homem verdadeiramente livre só quer o que pode e faz o que lhe agrada. Eis a minha máxima fundamental (ROUSSEAU, 1995, p. 76).

Para Rousseau é possível o resgate da liberdade em uma sociedade que degenera o ser humano. A resposta vem com sua proposta para a educação, em tudo diferente dos preceitos existentes no século XVIII. Ao invés do homem de negócios, devotado ao sucesso pessoal, o suíço quer a educação do homem total, livre das imposições das instituições sociais, mas capaz de mover-se nelas com desenvoltura. Rousseau quer uma formação capaz de despertar os instintos sociais dos indivíduos, "que cada particular não se julgue mais como tal, e sim como uma parte da unidade, e só seja perceptível no todo" (ROUSSEAU, 1995, p. 11).

Nem o sujeito submisso aos mandos religiosos, nem o indivíduo isolado e egoísta, mas o homem social, dedicado à comunidade, politicamente ativo, adaptável,

Cadernos GPOSSHE On-line, Fortaleza, v. 2, n. Especial, 2019.

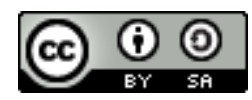


capaz de interagir como o mundo e aprender com cada nova experiência. De certo modo, Rousseau é precursor do conceito de educação ao longo da vida. Para tanto, desde a infância o indivíduo deverá aprender a utilizar todo seu potencial, desde a perfeição do corpo até o desenvolvimento pleno da cognição (ROUSSEAU, 1995). "O corpo não é mais pecaminoso, imoral; ele é necessário ao homem que viaja, trabalha, enfrenta as intempéries da natureza e se relaciona com outros homens" (DA MATA, 1998, p. 40).

O filósofo suíço entende ser a educação um poderoso instrumento para a formação política e nos apresenta, a partir de seus escritos, o processo de mudanças sociais de seu tempo. É preciso conceber indivíduos mais universais, dotados de capacidade de estabelecer juízos racionais sobre o mundo. O indivíduo moderno deve deter conhecimentos, mas também ser ativo, solucionar problemas inesperados e compreender a natureza para dominá-la. Para Rousseau, isso vem expresso naquilo que considerou que todos os grandes homens reuniram: "a força do corpo e a força da alma, a razão de um sábio e o vigor de um atleta" (ROUSSEAU, 1995, p. 132).

O projeto educacional de Rousseau é a expressão das mudanças sociais do século XVIII, mas é também uma âncora atirada aos séculos vindouros, que necessitaram voltar ao suíço a fim de melhor compreender não só as transformações em meio às quais o pensador produziu seus textos, mas os desafios lançados por ele para a formação do indivíduo burguês.

Embora haja diferenças entre eles, há uma intencionalidade clara nos escritos de Locke e de Rousseau: eles querem uma mudança no modo como a sociedade está organizada. Essa insatisfação com o existente leva-os a pensar possibilidades para uma nova forma de organização social. Diante do imenso desafio da mudança social, propõem um caminho: a razão como instrumento para a superação do obscurantismo e da tirania e a educação como sistematização dos novos conhecimentos exigidos para a construção do "novo homem". Porém, esse novo homem era já um projeto em discussão pelas mentes liberais que antecederam Locke e Rousseau.

\section{Desafio e Consequência: educação como parte de um projeto de sociedade}

Ao considerar um projeto, um ideal de ser humano, deve-se indicar o sentido utilizado para a palavra no corrente texto, posto que não seja incomum certa imprecisão em seu uso corrente. Um projeto não é uma projeção do futuro desejável pura e simplesmente a partir daquilo que se imagina como ideal, tampouco a indicação ou antecipação daquilo que está por ser realizado. Não se trata de deliberar o devir, mas, antes, da apreensão da materialidade existente, seus vãos, o entendimento dos limites e demandas da sociedade tal como é constituída e a voz humana indicando caminhos novos. Um projeto deve partir da realidade existente, apontando na direção daquela que se quer construir. Não há garantias de realização plena, uma vez que um projeto de ser humano novo para uma sociedade nova deve, necessariamente, ser aberto. A ideia de realização de um projeto já é conservação.

Tanto em Locke quanto em Rousseau, o propósito da educação é dar resposta a novas necessidades sociais: a formação do novo homem, diferente daquele da Idade Média. Como demanda histórica, esse novo homem não é uma ideia aleatória, fragmentada ou casual. Seu ponto de partida era o projeto de sociedade que se desenhava e que se entendia como melhor, mais perfeita, mais justa que a antiga. Para que o projeto de nova sociedade fosse efetivado, era indispensável a formação de indivíduos diferentes daqueles que eram o estofo de algo já antigo e que não 
surgem prontos, acabados e atuantes no mundo, é imperativo um processo de formação no qual o projeto de sociedade se concretize em um projeto de ser humano.

Esse processo histórico revela, entre outras questões, os embates entre classes sociais: de um lado, aqueles que se colocavam como classe emergente, progressista e revolucionária; de outro, os que dominavam, os conservadores, os caturros. Esse embate remonta ao século XVI, que entregou à história 0 desenvolvimento do mercantilismo e as intervenções do Estado Absolutista no comércio, prática muito combatida pela burguesia emergente, que reivindicava liberdade comercial. É a época em que viveu Michel de Montaigne (1533-1592) que, na apresentação de Nagel (2010), foi um defensor da liberdade, incentivador da superação do servilismo, crítico dos hábitos, costumes e vícios do Antigo Regime. Montaigne é o homem que "confirma a mudança como função humana, reforçando a ideia de que é preciso, sob novas coordenadas, modificar os filhos, os alunos, para a concretização efetiva de outra sociedade" (NAGEL, 2010. p. 55. Grifos da autora).

Montaigne (1972) critica duramente a formação que se baseia na pura memorização e repetição; na conservação estéril dos conhecimentos antigos, nos costumes desmedidos e nas relações viciosas e conspícuas dos nobres. "Nosso espírito, no sistema que condeno não procede senão por crença e adstrito às fantasias de outrem, servo e cativo de ensinamentos estranhos" (MONTAIGNE, 1972, p. 81). O humanista francês refere-se aqui a um projeto de sociedade decadente, condenado pelas relações sociais e que não é mais capaz de responder aos anseios dos indivíduos. Esse projeto de sociedade pressupunha a formação de um perfil, de um sujeito, cujo fundamento estava nas relações sociais de vassalagem, no servilismo, no Estado Teocrático.

$\mathrm{Na}$ contramão dessa tradição, Montaigne (1972) defende um novo projeto social, um ideal que negue as relações sociais consideradas antigas, caducas, em extinção. Mas essa negação, embora refira-se à totalidade das relações sociais do medievo, dirige-se à formação de indivíduos novos. É preciso um novo ser humano para negar a velha sociedade e construir uma nova. Montaigne (1972) vê na educação que modifique as tradições da antiga formação, que construa uma nova natureza social, que não se contenha nos ensinamentos que tornam as pessoas cativas, 0 caminho para esse novo projeto de ser humano.

O instrumento dessa formação é a ciência. A nova sociedade demanda indivíduos capazes de lidar com a realidade a partir de bases diferentes daquelas ditadas pelo costume, pela religiosidade, pelos preconceitos e pelos dogmas, em seu lugar, a lógica, a física, a geometria e a retórica (Montaigne, 1972). O que se quer é o ensino daquilo que há de mais avançado nas ciências daquele tempo, sem que isso destrua a tradição de conhecimentos dos antigos, mas que supere a ignorância e o obscurantismo. A tarefa é hercúlea e Montaigne sabe bem que semear homens é algo fácil, porém, "depois de nascidos, educa-los e instruí-los é tarefa complexa, trabalhosa e temível" (MONTAIGNE, 1972, p. 80).

O projeto de ser humano em disputa aqui expõe não só os desequilíbrios da formação humana do Antigo Regime, mas também as mazelas de uma sociedade em crise, para a qual as próprias instituições, que outrora a sustentavam, apresentam-se como óbices ao desenvolvimento. $O$ entendimento da sociedade antiga encaminha a intencionalidade de formar um novo tipo de indivíduo, porque o velho projeto expressa a estagnação. Esse novo homem precisa cultivar mais dúvidas que certezas: "apresentem-se-lhe todos [os princípios] em sua diversidade e que ele escolha se 
puder. E se não puder fique na dúvida, pois só os loucos têm certeza absoluta da sua opinião" (MONTAIGNE, 1972, p. 80).

Para Montaigne (1972), a educação tem papel transformador. Por isso mesmo, deve dirigir-se à formação de pessoas críticas à sociedade existente. É com a capacidade analítica e crítica da razão que o indivíduo poderá mover-se com mais desenvoltura, relacionando-se com outros indivíduos também críticos; produzindo conhecimentos novos, diferentes e desenganadores em relação ao mundo; transformando as bases da sociedade para encaminhar o futuro, entendido como superação qualitativa do estágio no qual se encontra a sociedade.

No século XVI, Montaigne (1972) expressa uma tendência: o descontentamento com a forma pela qual a sociedade estava organizada. Aponta também uma direção, uma intencionalidade: a educação como protagonista em um projeto de superação do obscurantismo, a partir da ciência. No século XVII, essa tendência aparece em John Locke (1986), que apresenta uma proposta para a educação do indivíduo entendido como "homem de negócios", livre para pensar e para mover-se no mundo. No século XVIII, Rousseau (1995) demonstra o mesmo descontentamento com o Antigo Regime, apontando já os desequilíbrios da sociedade emergente. O caminho indicado por Rousseau (1995) passa também pela educação capaz de superar as diferenças sociais e formar um indivíduo para viver em sociedade, um "homem total".

O projeto de uma nova sociedade, que tem seus primeiros esboços traçados no século XVI, só ganha formato ao final do século XVIII, época em que as duas grandes revoluções (industrial e francesa) transformam dramaticamente o mundo. Hobsbawn (2011) explica que, se de um lado, a Inglaterra forneceu o explosivo econômico para romper com as estruturas sociais tradicionais, foi a França que deu a ideia, os princípios e a política contra os quais, ou a favor dos quais, a maior parte do mundo se mobiliza. Em um sentido lato, o século XVIII apresenta duas revoluções complementares (HOBSBAWN, 2011).

A Revolução Francesa torna imperiosa a formação de um novo tipo de indivíduo. Encontram-se, após séculos de embates, a sistematização, a intencionalidade e a metodologia para concretizar o projeto de mudanças históricas da nova sociedade. Foi Condorcet (1743-1794), filósofo e matemático francês, membro do comitê de instrução pública da assembleia legislativa durante a revolução, quem apresentou ideias de um projeto educacional público, laico, gratuito e autônomo em relação ao Estado. Embora a educação não seja, evidentemente, a pedra de toque da revolução, em Condorcet (2010) é possível verificar que o projeto do "novo homem" para o "novo mundo" ganha contornos, materializa-se em uma proposta para a formação dos indivíduos que, deseja-se, sejam livres das relações aristocráticas, capazes de ascender socialmente pelo mérito advindo do conhecimento. Como, então, em Condorcet, esse novo indivíduo revolucionário deveria ser encaminhado?

Antes de tudo, é pela instrução que as nações se preparam objetivamente para o futuro. O conhecimento das leis da natureza (ciência), das artes, das novas culturas, deve constituir a base a partir da qual se apoia a educação. A nação que "tornar-se digna de obedecer às ordens da razão, que não for submissa a esse jugo de ferro que o hábito impõe à estupidez, aproveitará as primeiras lições da experiência e até mesmo prevenirá esses males" (CONDORCET, 2008, p. 31).

A razão é apresentada como a arma fundamental da luta pela superação do obscurantismo. A nova sociedade que se impunha, a fim de superar os limites do passado, dava nascimento a instituições também novas e, com Condorcet, delineava a instrução pública como uma função precípua do Estado, um dever da sociedade

Cadernos GPOSSHE On-line, Fortaleza, v. 2, n. Especial, 2019.

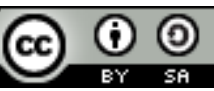


para com seus cidadãos. A educação recebe aqui contornos políticos. Ao ser endereçada à instrução (em diferentes graus, é verdade) de todos os cidadãos, é concebida como instrumento de formação moral contra o servilismo, contra a ignorância e a favor da igualdade. "Seria, pois, importante ter uma forma de instrução pública que não deixasse escapar nenhum talento sem ser percebido e que oferecesse, nesse sentido, todos os auxílios reservados até hoje apenas aos filhos dos ricos" (CONDORCET, 2008, p. 26).

Sendo as ciências concebidas como o instrumento de que se servem os homens na descoberta da verdade, desenvolver talentos antes ignorados é uma direção política claramente oposta ao confinamento do saber a poucos indivíduos. Não é só a formação de gênios que descubram novas verdades, mas, antes, dar "a um maior número de jovens espíritos os meios de cumprir o seu destino" (CONDORCET, 2008, p. 27).

Como direção política, cabe ao Estado viabilizar a instrução pública. Ao apontar a igualdade como elemento central da Revolução Francesa, torna-se função do Estado assegurar o aperfeiçoamento dos cidadãos, tornando-os capazes de compreender seus direitos e deveres, de desenvolverem seus talentos e de efetivarem a igualdade política. "É preciso dar a todos, igualmente, a instrução que é possível ser estendida a todos, mas não recusar a nenhuma parcela dos cidadãos a instrução mais elevada que é impossível fazer aquinhoar à massa ativa dos indivíduos" (CONDORCET, 2008, p. 23).

A razão toma o lugar do dogma, a ciência toma o lugar da intuição e da religiosidade. Para Condorcet (2008), a ciência deve constituir a base da formação de professores (mestres) que atuam na instrução comum. Por esse meio, Condorcet (2010) entende ser possível ensinar às pessoas aquilo que é necessário que todos saibam: ler e escrever; a gramática; as noções de aritmética; as mensurações; os procedimentos de agricultura e noções de arte. O novo homem deveria ser formado por mestres capazes de transmitir, nas escolas, as verdades científicas.

Condorcet (2008) credita ao Estado a função de regular o ensino primário, mas não a regulação do ensino das ciências. O novo poder, agora público, deve incumbirse do propósito de superar o obscurantismo, promovendo uma instrução pública capaz de livrar os indivíduos de todas as correntes de autoridade, laços religiosos ou políticos. Destaca-se a independência de pensamento: "Deve-se mesmo ousar examinar tudo, discutir tudo, ensinar tudo" (CONDORCET, 2008, p. 242).

Importante ressaltar a autonomia de que deve gozar a instrução pública. Embora ao Estado caiba a função de garantir todas as condições necessárias ao funcionamento dessa instrução, não deve ter qualquer ingerência sobre ela. Nas palavras de Condorcet: "nenhum poder público deve ter nem autoridade nem mesmo crédito para impedir o desenvolvimento de novas verdades e o ensino das teorias contrárias à política particular ou aos interesses momentâneos" (CONDORCET, 2010, p. 25).

O projeto elaborado por Condorcet realiza em um documento formal anseios alimentados pela burguesia emergente em sua luta contra o obscurantismo medieval. Embora jamais tenha sido efetivado, todas as propostas para educação, durante e após a Revolução Francesa, basearam-se nas prescrições do humanista francês. $\mathrm{Na}$ avaliação de Alves:

Não se pode omitir que este documento, apresentado inicialmente na Assembleia Legislativa, em 30 de janeiro de 1792, foi também a base das propostas de Lanthernas, na Convenção Girondina, e de Romme,

Cadernos GPOSSHE On-line, Fortaleza, v. 2, n. Especial, 2019.

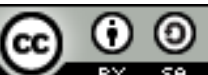


na Convenção Jacobina. Possivelmente, o Rapport de Condorcet foi o documento relativo à instrução pública mais lido e discutido pelos segmentos dirigentes da Revolução Francesa (ALVES, 2001, p. 55-6, grifo do autor).

Embora a disputa política no interior do próprio governo revolucionário tenha inviabilizado a educação/instrução para todos os cidadãos nos moldes propostos por Condorcet (Alves 2001), o Rapport é a concretização do projeto educacional da sociedade burguesa, haja vista a influência que ainda mantém sobre a organização geral da educação. Em seu nascedouro, a educação/instrução pública burguesa visa municiar o indivíduo com conhecimentos fundamentais e com as habilidades e destrezas necessárias à formação de força de trabalho qualificada para as necessidades do capital.

Essa discussão, ainda conforme Alves (2001), atravessa o século XIX. As habilidades de ler e escrever, os conhecimentos rudimentares de matemática e a formação inicial nas humanidades e ciências consolidam a educação/instrução pública como a mais relevante instituição social destinada à formação do cidadão. "Nesse sentido, ela era entendida como um recurso decisivo para a consolidação e preservação da república, bem como para a derrota definitiva dos inimigos feudais" (ALVES, 2001, p. 130). No século XIX, com a Revolução Industrial consolidada, com a urbanização, com as relações entre capital e trabalho sedimentadas, a educação/instrução ainda é instrumento de luta contra o obscurantismo medieval, ainda é preciso defender o estado burguês, ainda é indispensável reafirmar o indivíduo emancipado politicamente. O projeto e as mudanças que desde o século XVI foram objeto de disputa efetivam-se no século XIX. Embora de forma diversa daquela preconizada por Montaigne, Locke e Rousseau e até por Condorcet, a essência, $O$ fundamento, foi mantido: a educação/instrução é o instrumento de lutas contra o obscurantismo.

\section{Considerações Finais}

Ao retomar elementos como o caráter histórico da educação, seu inevitável perfil de mudança e o fato de que todo processo educacional esteja vinculado a um ideal de sociedade, apreende-se que, para a burguesia em ascensão, ela fazia parte do projeto de um novo mundo mais civilizado, mais justo e melhor que a velha forma feudal. A constituição da instituição educacional como instrumento para a superação do obscurantismo é um importante avanço em direção à emancipação política.

Fica evidente, ao longo da exposição, que, para uma transformação social mais profunda, é preciso mudar indivíduos: a superação do obscurantismo é uma tarefa para sujeitos enriquecidos de conhecimentos científicos, humanísticos e artísticos, ou, uma subjetividade mais rica e que não se reduza a dogmas de fé e/ou a superstições. Acima de tudo, para a burguesia, um indivíduo que entenda a si mesmo como independente dos laços feudais, que seja autônomo para negociar, livre para explorar seu mundo e capaz de antecipar as intenções dos outros.

Forjar o novo indivíduo, uma nova subjetividade, obrigou a realização de mudanças de direção na formação humana. As pessoas que soubessem ler, escrever, realizar operações matemáticas e reconhecer rudimentos das ciências seriam mais capazes de realizar o projeto de uma sociedade nova. Em um contexto de mudanças sociais, a educação assumiu um papel central. Desde as reflexões de Montaigne, passando pelas prescrições de Locke e Rousseau, até a efetivação de uma proposta 
educacional por Condorcet, a formalização de um projeto educacional capaz de encaminhar uma subjetividade que se pretendia mais rica ganha forma na instituição formal, na escola pública.

A escola pública, como instituição da sociedade burguesa, não se estabelece de imediato, mas conforme demandas e condições materiais em cada país e em cada momento histórico. É assim que na Inglaterra ela tenha características diferentes às da Alemanha ou França (ALVES, 2001). Uma constante é que a instituição educacional formal se disseminou por toda Europa e, já no final do século XIX e início do século XX havia projetos de educação pública em boa parte do mundo.

Porém, um processo educacional cujo foco fosse a formação racional dos indivíduos emancipados politicamente foi um projeto realizado apenas parcialmente. O projeto educacional burguês teve como pressuposto a formação de homens e mulheres diferentes daqueles desejados pelo medievo, mas sua efetivação garantiu uma emancipação frágil: por um lado produziu indivíduos mais independentes, autônomos e letrados; por outro, submetidos aos interesses do capital. O obscurantismo medieval só foi superado na liberação da força de trabalho das amarras feudais.

A concretização de um sistema educacional burguês não encaminhou a superação do obscurantismo. Embora a ciência tenha conhecido importantes avanços a partir do século XIX, eles ainda estão limitados a alguns poucos centros formativos. A frequência dos indivíduos à instituição educacional formal burguesa não produziu subjetividades mais ricas, mas dirigiu-se a uma formação com objetivo de qualificar a força de trabalho que alimenta o apetite voraz da produção capitalista. Os rudimentos de ciência, ler, escrever e conhecer matemática, para os trabalhadores, não se dirigem à emancipação, mas ao uso pragmático, utilitário, de intensificar a extração do mais valor.

Quando a burguesia sedimenta seu domínio sobre os meios de produção, logo deixa de ser revolucionária, conservando relações sociais baseadas na contradição entre capital e trabalho. A outrora classe revolucionária quebrou um de seus instrumentos contra o obscurantismo medieval quando reduziu a formação dos indivíduos, através da educação formal, à mera qualificação para o trabalho. Antiga classe transformadora, tornou-se segmento obscurantista da sociedade. As instituições burguesas, por seu turno, assumiram as feições daquilo contra o que lutaram em seu momento de ascensão: ao invés do combate contra o obscurantismo, tornaram-se mantenedoras da submissão; ao invés da formação de subjetividades ricas, a mera instrumentalização dos indivíduos subservientes às necessidades do capital com sua força de trabalho; ao invés da consciência crítica, a naturalização das relações sociais desiguais.

Evidencia-se, também, a partir do texto aqui apresentado, que, observadas as condições objetivas em cada momento histórico, a educação se constitui como importante instrumento de luta contra o obscurantismo. É pela educação, sistemática, parte de um projeto de mudanças sociais, que o indivíduo se torna capaz de lutar contra o estranhamento. Parafraseando Marx, a educação é a arma da crítica sem a qual qualquer mudança social torna-se inviável. O contexto atual, de violentos ataques à educação, bem como a inexorável conformação à qualificação profissional do indivíduo ao mercado de trabalho, é uma expressão do recuo do projeto emancipatório defendido pela burguesia em sua fase revolucionária. Para os trabalhadores, esse é um caminho que afoga a vida, empobrece e rebaixa as expectativas por um mundo melhor, reduz ao pragmatismo aquilo que deveria ser o enriquecimento dos sentidos humanos. 
Para os trabalhadores, a luta contra o obscurantismo deve ser a luta pelo acesso ao que de mais avançado se produziu, desde os conhecimentos humanísticos até os científicos e os artísticos. O projeto para uma nova sociedade, mais justa, diferente e mais humanizada, precisa considerar formas educacionais que superem a já caduca e inviável sociedade burguesa, cujas instituições não promovem o desenvolvimento humano, mas se tornaram seus óbices. A emancipação humana é um horizonte para o qual se deve dirigir a formação do ser humano desejável para a nova sociedade e a educação é um dos instrumentos fundamentais da luta contra o obscurantismo que avança sobre nossas cabeças.

\section{REFERÊNCIAS}

ALVES, Gilberto Luiz. A Produção da Escola Pública Contemporânea. Campinas: Autores Associados; Campo Grande: Editora UFMS. 2001.

CONDORCET. Jean-Antoine Marie Nicolas de Caritat, Marquis de. Cinco Memórias sobre a Instrução Pública. São Paulo: Editora UNESP, 2008.

CONDORCET. Jean-Antoine Marie Nicolas de Caritat, Marquis de. Relatório e Projeto de Decreto sobre a Organização Geral da Instrução Pública, apresentados à Assembleia Nacional em Nome do comitê de Instrução Pública em 20 e 21 de abril de 1792. IN: ALVES, Gillberto Luiz. Escritos sobre a Instrução Pública: Condorcet: reflexões e notas sobre a educação. Campinas-SP. Autores Associados, 2010, PP. 21-38.

DA MATA, Vilson A. Da Força Física à Estética Corporal: as mudanças nas relações sociais retratadas no corpo. IN: Revista da Educação Física/UEM: v. 9; n.1, pp 35-43, 1998.

HOBSAWN, Eric. A Era das Revoluções: 1789-1848. São Paulo: Paz e Terra, 2011.

KLEIN, Lígia R.; SILVA, Graziela L. R da.; DA MATA, Vilson A. Alienação ou Exclusão: refletindo o processo de "inclusão" na Educação de Jovens e Adultos. IN: FACCI, Marilda G. D.; MEIRA, Maria E. M.; TULESKI, Silvana C. A Exclusão dos Incluídos: uma Crítica da Psicologia da Educação à Patologização e Medicalização dos Processos Educativos. Maringá: Editora da Universidade Estadual de Maringá; 2012, pp. 211 a 232.

LEONTIEV, Alexis. O Desenvolvimento do Psiquismo. Lisboa: Livros Horizonte, 1978.

LOCKE, John. Pensamientos Sobre la Educación. Madrid: Ediciones AKAL; 1986.

MARX, Karl; ENGELS, Friedrich. A Ideologia Alemã. São Paulo: Boitempo, 2013.

MÉSZÁROS, István. A Teoria da Alienação em Marx. São Paulo: Boitempo, 2006.

MONTAIGNE, Michel de. Da Educação das Crianças. Ensaios. São Paulo: Abril Cultural, 1972, p. 79-92 (Col. Os Pensadores).

NAGEL. Lízia Helena. Condições de Educabilidade para uma Nova Sociedade: reflexões básicas. Germinal: marxismo e educação em debate, Londrina, V2, № 2, p. 54-68, Ago. 2010.

ROUSSEAU, Jean-Jacques. Emílio, ou, Da Educação. São Paulo: Martins Fontes; 1995. 
ROUSSEAU, Jean-Jacques. Discurso sore a Origem e os Fundamentos da Desigualdade entre os Homens / Discurso sobre as Ciências e as Artes. Trad. Lourdes Santos Machado. São Paulo: Nova Cultural, 1999. Os Pensadores.

SAGAN, Carl. O Mundo Assombrado pelos Demônios: a ciência vista como uma vela no escuro. São Paulo: Companhia das Letras, 2002. 